\title{
Group guidance - is it time to flock together?
}

\section{Susan Meldrum}

This article calls for delivery models which encourage the collective career learning of groups to be brought to the centre stage of career guidance practice. It challenges the long term focus of the sector on the one-to-one guidance interview and considers why group work is seen as a support activity for the majority of practitioners. The group integrative narrative approach (GINA) which was developed by the author will be introduced as a model of small group work and its potential to act as a vehicle to steer group career learning will be discussed.

\section{Introduction}

There is an emerging interest in group guidance in various forms being used as a contender to challenge traditional one-to-one approaches to career guidance. The one-to-one guidance interview has been the delivery model of choice in the career guidance profession for over forty years in the UK and elsewhere but despite a body of evidence to support its efficacy (Whiston, Sexton and Lasoff 1998; Maguire and Killeen 2003; Brimrose, Barnes and Hughes 2008; Hughes and Gration 2009; Hooley 20I4), it is considered a costly and labour intensive delivery method.

Thomsen (2012) sees the one-to-one interview as placing too much importance on the individual and makes a call for approaches which encourage collaborative problem solving being brought into sharper focus. Westergaard (2013) sees the emphasis on one-to-one approaches as a 'lost opportunity to seek and challenge new and innovative ways of working' (2013: 175). Di Fabio and Maree (2012) want to start a 'global recognition' that group based career guidance models can develop career learning skills.

Career learning involves the lifelong process of individuals, groups or communities building, knowledge, skills, and attitudes through a range of activities, experiences and interactions to enable them to take charge of their career development.

This article will consider the progress of the group work movement in the career guidance field, its potential to develop career learning and the attempts to bring it closer to the centre stage of practice. It will then introduce the group integrative narrative approach (GINA), a model of group guidance developed by the researcher and will draw on evidence from group counselling approaches in the wider field of counselling and the initial results of a pilot study using the model in two secondary schools in Edinburgh to support its efficacy.

Whilst it is anticipated that the one-to-one approach will be dominant for many years, it is suggested that group approaches which have the potential to draw on the skills of practitioners and develop the collective career learning skills of groups should play an increasingly important role.

\section{Group work effectiveness}

Group work has been used extensively as a guidance activity in the UK and elsewhere for over forty years. However, in contrast to the one-to-one approach there has been a lack of clear guidelines or approaches to support the delivery of group work. Offer (200I) 
thought that group work in schools for instance could be 'anything on a continuum from public speaking to interventions very close to individual interviewing' (200I:60).

Career guidance practitioners are highly competent in the use of counselling and coaching skills such as active listening, questioning and paraphrasing and are quickly able to build up interpersonal relationships with clients. These skills do not always transfer easily to group work and working with young people in schools in a classroom based environment for instance requires practitioners to be adaptable, resilient and confident enough to deal with the challenges of behaviour, group dynamics and the differing needs of learners.

A resistance and lack of confidence amongst practitioners to fully utilise group work has been the case for many years and Higgins and Westergaard (1998) believed that if group work is to become more than a support activity it needs to be 'in style, content and aims more similar to the guidance interview than is currently the case' (1998:4).

In Italy narrative approaches more associated with one-to-one interviewing such as Savickas (2012) have been used with groups. In one such study with a group of adults (Di Fabio and Maree 2012) it was highlighted that the group approach was effective at being able to draw on other group members for peer support and feedback. This led to the study group displaying a significant decrease in career decision making difficulties compared to the control group.

In Denmark there is an emerging interest in group and collective approaches challenging the traditional individualistic approaches to practice. Thomsen (2012) in Career Guidance in Communities carried out empirical studies to examine the effectiveness of group approaches in two 'communities' in Denmark - with young people in a high school and with adults in a factory. It was found that people saw each other as resources and coped with their issues and challenges collectively. The goal of career guidance is seen here to be moving towards developing the career learning of communities.

In the UK personal learning and development (PLD) group work has been developed for use in in the field of career guidance in recent years and Westergaard (2009) introduced the FAAST model. The FAAST model (focus, aims, activities, structure, and techniques) is considered 'guidance' group work as there is an emphasis on the building up of interpersonal relationships within the group by using counselling and coaching techniques and the structure is based on one-to-one approaches. It bears some resemblance to models from the field of teaching and training by encouraging the use of a pre-prepared lesson design and activities.

A small scale study with a focus group of practitioners using the FAAST model (Westergaard 2013) indicated that the model increased confidence levels of practitioners. In addition practitioners felt that the model was able to make participants feel that 'they were not alone' and highlighted the sharing of ideas with each other as another benefit of the approach. However the practitioners felt that for the groups to work well they needed to have a common task or concern, otherwise some of the pupils could feel stigmatised. Practitioners felt that the attention and time were not shared equally between participants and some would gain more from the sessions than others. Further research with groups of practitioners would strengthen the potential of this model.

The FAAST model of PLD group work and the approaches from Italy and Denmark appear to be promising moves towards bringing group work closer to the centre of practice. However, certainly in the case of the FAAST model, it is questionable whether a pre-planned lesson design would offer many opportunities within the group work to build up meaningful interpersonal relationships and the approach seems aimed at class sized groups of ten or more. An adapted model with a more fluid agenda for use with smaller groups would seem to be of benefit.

\section{Small group work}

Small group work, which according to Law (1996) 'straddles the boundary between group work and oneto-one interviewing' (1996:212), could be a bridge between the two approaches. It offers the benefits of group work such as peer support and group learning coupled with the potential to build up high quality interpersonal and social interactions usually only 
possible with the one-to-one approach. However, the potential of small group career guidance to innovate practice has so far been largely overlooked.

There is very little evidence which looks at the effectiveness of small group guidance in the field of career guidance. That which does, a meta-analysis comparing group counselling with structured class group work (Whiston, Brecheisen, Stephens 200I), suggests that structured groups produce better outcomes than non-structured career counselling groups. However the unstructured group counselling in the studies appeared not to follow any model or structure.

Turning to the wider field of counselling provides more promising results and there is a substantial body of evidence to suggest that group guidance and counselling can be as effective as, or more effective than, one-to-one approaches (McRoberts, Burlingame and Hoag 1998; Smith, Glass and Miller 1980; Toseland and Sporin 1986).

Models adopted tend to be modified one-to-one models from the field of counselling rather than group work planning models from teaching and learning. Carl Rogers (196I) adapted his person centred approach, initially as a saving of time, to group work and this was instrumental in the development of the group work movement in the 1960s.

A number of studies have been carried out over the years looking at the effect of group dynamics on individuals within a group. Bales (1950) found that group members displayed helping behaviours and sharing of ideas which was above average compared to one-to-one interactions in terms of quality of decisions and the effectiveness to take action. However it was cautioned that $40-50 \%$ of comments were consistently made by the most talkative individual within the group and $25-30 \%$ by the second most talkative.

Taking these limitations into consideration there is evidence from the wider field of counselling that small group guidance has the potential to be an as effective or more effective mode of delivery as the one-to-one approach.

\section{The model}

The GINA model was developed by the researcher by a combination of research in the field, observations over many years of working as a guidance practitioner and more recent experience teaching counselling and coaching skills to students.

The model uses a theoretical integration of counselling and coaching models (Rogers, 1961; Kidd 2006; Whitmore, 2002; Savickas, 20I2) with learning theory (Kolb, 1984) and PLD group work (Westergaard 2009). It draws from group counselling models taken from the wider field of counselling which use modified one- toone approaches rather than models from the field of teaching or training. The model is outlined in figure I below.

The GINA model is underpinned by a constructivist approach, based on narrative life design counselling using the Career story interview (Savackis 20I2). Traditionally the field of career guidance has used a positivist approach with the career practitioner as the expert and the client as the passive receiver of advice. A constructivist approach, on the other hand, is the 'the merging of the social and the psychological worlds through experience and co-operation' Young and Collin (2003). In other words, seemingly random social interactions and experiences (or threads) from an individual's personal and work lives start to form interconnecting patterns and hold meaning. A small group counselling and coaching model benefits from taking this approach as the practitioner and the group members act as the co-facilitators within the group each taking an active part.

The Career Story Interview (Savickas 20I2) offers clients the opportunity to explore the connections between personal characteristics, developmental processes and life 'stories' or events that people repeat, revisit and retell to take a different path or way forward. It explores six main questions - role models, television shows or magazines, hobbies, school subjects, recollections of earliest memories and a life motto. Each question has a clear purpose, for instance, the question related to role models can bring out how the client sees themselves and their approach to life. Narratives discussing early memories can reveal 


\section{Building the Relationship}

- Seek consensus to try 'something unusual'

- Outline GROW stages and narrative approach

- Agree working alliance/session timing/ confidentiality/ ground rules

- Group discussion to identify joint goals of group [flipchart]

\section{Telling the Story}

- Explore questions [written exercise]

- Role models - admire/ cool characters

- Hobbies/ interests

- Magazines/TV

- Books/ films - plot

- Earliest memories

- School subjects

- Summarise stories, restating key words/ verbs used

\section{Actions}

- Revisit goals, summarise whole discussion and allow space for group to reflect

- Agree with group what they should be doing next

- Realistic relevant targets with timescales

- Evaluate - using ratings scales how useful has group found session? How motivated are they to act?

major life concerns or preoccupations which could be blocking progress; favourite television shows can offer insights into the clients preferred job roles or environment, for instance exploring the outdoors, or a fast paced office environment. Taken together, by forming patterns, threads and inter-connections, clients should begin to be able to build up a 'meta-narrative' or 'multiple-life stories' of their self within society.

This approach has been used in the UK by Reid and West (20II) and initial research with the use of the life design model on a one-to-one basis suggest that it helps people think in deep and unexpected ways about their concerns and approach to life. More recently Reid (2016) has adapted the approach and some of the questions following further research and feedback that clients find some of the questions challenging to answer.

Career learning is achieved by the career practitioner or facilitator encouraging participants to learn cooperatively. Group members use each other as a

\section{Abstract} conceptualisation
- Group 'playful' exploration of new ideas using tools such as visualisations, cards, diagrams

- Group work together to build new goals or 'themes' 
resource; evaluate each other's ideas, stories and choices and work together to achieve shared goals. This form of experiential learning is based around the Kolb (1984) cycle. The participants actively come up with joint goals for the session (concrete experience) followed by taking part in the narrative written exercise. These experiences form the basis for reflection and the group members have the opportunity to discuss each other's stories (reflective observation), and retell their stories, evaluate their ideas and help each other achieve their goals (abstract conceptualisation). The GINA model is explained to the participants making it possible for group members to continue to retell their stories and re-evaluate their options by a cyclical pattern of previous experience, thought and reflection (active experimentation).

The career management skills framework (Skills Development Scotland 2012) is a career learning model which aids the career learning process by offering a scaffold of competencies to build on. These competencies involve developing four broad themes - a sense of self within society; awareness of skills, strengths and achievements; broadening horizons; and developing support networks and relationships. This framework is widely used in Scotland and was influenced by international 'blueprint' models in Australia, USA and Canada.

The GINA model uses person centred counselling techniques (Rogers 196I) including building a counselling relationship with a number of 'core conditions' of empathy, unconditional positive regard and congruence and using a range of skills such as active listening, asking open questions, and reflecting back feelings to encourage open dialogue.

The structure of the approach is based around the GROW coaching model (Whitmore 2002) and adapted to the career guidance field by Yates (2014). The structure includes agreeing a purpose or contract or goal, followed by exploring the story, exploring options and action planning. This type of structure is used extensively by guidance practitioners and in Scotland a coaching approach to guidance (Skills Development Scotland 2012) is used for one-to-one interactions.

\section{The research}

The GINA model was piloted in small scale study using participatory action research (PARS) based on the Kemmis (1982) model.A group work session was offered to two small groups of S5 pupils (age 16-17) in two separate secondary schools in Edinburgh followed by a focus group a week later. The research sought to answer the following questions -

- To what extent does the model develop the career management skills of the young people?

- What are the potential benefits and limitations of career guidance delivered in a small group?

The group work sessions appeared to develop the sense of self and skills career management competencies. The use of the career construction questions and in particular discussing role models seemed to draw out patterns between qualities participants admired and who they were or would like become. For instance, although two participants admired same person, the footballer Ronaldo, when probed by the facilitator to tell the story of memorable football match one used verbs such as 'exciting and entertaining' while the other focused on him being 'fit, skilful and driven'. This led onto discussions about work environments and preferences.

Another participant admired the actor David Tennant in his role as DrWho. He told the story of him being 'energetic, on his feet, funny, doing amazing things, saving people and being a bit crazy' (participant 2). Later in the session others group members helped him see the links between these qualities and his idea of working in emergency services.

The groups seemed to be able to help each develop horizons and network competencies by building narratives, seeing patterns emerge between a range of experiences, interactions and interests and working together to identify action plans for each other. For instance one participant when asked about a favourite magazine told of reading PC Gamer magazine and from a young age liking 'building things and learning how things work' (Participant 3).

Another group member identified engineering and added - 
My dad does software engineering at the place with the planes, Selex. They put him through university. Before that he was programming for radars and stuff but that is still engineering. My dad now has school leavers working for him and they go to university two days a week like he did.

(Participant I)

Participant 3 later commented in the focus group -

I would never have thought about computing or engineering or something like that, I would not go into that detail but it was cool and for someone who didn't know what they wanted to do... it was well interesting as I was able to know what other people were like. The group makes people think about career paths that they hadn't thought about.

(Participant 3)

There was a sense that the group were able to come up with a higher number and a higher quality of options compared to one-to-one interactions as Bales (1950) found in his groups. However it is difficult to draw a clear conclusion from this without a direct comparison with one-to-one interactions. This would merit further research.

In relation to the second research question, the majority of the participants appeared to benefit from sharing ideas, thoughts, and feelings with their peer group. In the focus groups comments such as 'you work as part of a team so come up with more ideas' (participant 2) and 'we have all worked well together. I think we get more sympathy that way' (participant 5). There was a sense of feeling that others were experiencing the same issues 'makes you feel that you are not alone in feeling a certain way' (participant 4).The majority commented that felt more confident, motivated and had changed their attitude towards making decisions for themselves. 'It has been quite useful to get me to understand where to go as I really wasn't thinking about it' (participant 3). This supports the evidence from the use of the FAAST model (Westergaard 20I3) and Di Fabrio and Maree (2012).

However there were a number of limitations found in the pilot study. It was noted, similar to Reid's
(2016) finding that some of the participants found the questions difficult to answer, 'I don't think about these things on a daily basis' (participant 8) and others group members expressed difficulty coming up with what they thought in group situation. Like Westergaard (2013) they found it difficult to ensure that the discussions were relevant for whole group and there were some compromise with the level of 'depth' of discussion in the groups compared to one-to-one interactions.

More significantly, a small minority of group members expressed feeling uncomfortable in the group situation and appeared to contribute very little. This supports the evidence from Bales (1950) and Westergaard (2013) who found that some would gain more from the group experience than others. This creates a challenge for the facilitator and highlights the need for training in the use of the model. The session should begin with clear expectations and ground rules for each of the participants. This should include individuals being able to express if they feel uncomfortable during the session and the right to leave the session when they want. This also throws up the suggestion that small group work is less suitable for some and alternative larger group or one-to-one options should be available.

Despite an even spread of gender being recruited for each group, there was a minority of females who then took part. It is difficult to conclude whether this had a positive or negative effect on the dynamics within the group. The female in the first group seemed to play a significant part in co-facilitating the session but in the second group the female contributed very little. This would merit further research.

From the results of this initial pilot study, the GINA model was seen to be effective at developing the group's career management skills, easing the pressure of participants through empathy, the sharing ideas and through peer support. This in turn was seen to possibly lead to higher quality decisions, improve motivation, confidence, attitude and effectiveness to take action. The model also has the potential to enable participants to think in new or unexpected ways about values and outlook on life. However there are a few limitations and the approach will not be suitable for all. 
The results of this research should be treated with caution, however, as it has so far only been piloted with two small groups of school pupils. It would benefit from further studies being carried out over longer periods of time with a larger number of groups. A comparison of the GINA model with the one-toone approach would also be of benefit as would the use of the model with different client groups.

\section{Conclusion}

The long term focus of the career guidance sector on the one-to-one interview is costly to the sector and inhibits the development of new and emerging approaches. Group guidance is one such emerging approach and this article has discussed its potential to develop the collective career learning of groups.

There are a number of new group approaches globally such as career guidance being used to connect people and their experiences to their communities in Denmark (Thomsen 2012), using a narrative approaches in Italy (Di Fabio and Maree 2012) and the development of personal learning and development group work in the UK (Westergaard 2009). These are a few of a number of approaches which have the potential to steer the group work movement and bring it closer to the centre of practice than is currently the case.

The GINA model which was heavily influenced by the above approaches and from group counselling models in the wider field of counselling was introduced as a model of small group guidance. It was suggested that it is able to bridge the gap between group work and the one-to-one approach by using high quality interpersonal collaborative interactions to develop group learning. Initial pilot findings indicate that it is effective at developing the career learning skills of the group.

Looking forward it is anticipated that the above approaches will play an increasingly important role in career guidance practice but only if researchers, practitioners, policy makers and guidance providers support their ongoing development.

\section{References}

Bales, R.F (1950) Interaction Process Analysis, Cambridge: MA Addison

Beebe, S.A and Masterson, S.T (2006) Communicating in small groups: principles and practices, 98th edition, Boston: Pearson Education

Brimrose, J, Barnes, S.A. and Hughes, D (2008) Adult career progression and advancement: a five year study of the effectiveness of guidance, London:Warwick Institute for educational research, DfES

DiFabio, A, Maree, G (20/2) Group-based life design counselling in an Italian context, Journal of vocational behaviour, 80 (I): 143-150, http://dx.doi.org/10.1016j. jvb.201 I.06.00I

Egan, G (20l4) The skilled helper:A problem management and opportunity development approach to helping, 10th edition, Belmont C.A: Brooks/ Cole

Higgins, R and Westergaard, J (1998) In search of guidance models for the group context, In Occasional papers in careers guidance, No.2; A collection of professional papers by staff at the College of Guidance Studies, Stourbridge: Institute of Careers Guidance Hooley, T (2014) The evidence base on lifelong guidance, Jyvaskyla, Finland: European Lifelong guidance policy network

Hughes, D, Gration, G (2009) Literature review of research on the impact of careers and guidance-related interventions, Literature review (CfBT Education Trust), CfBT Education Trust, Reading, available at http://www. cfbt.com/en-GB/Research/Research-library/2009/revidence-and-impact-careers-and-guidance-relatedinterventions-2009

Kemmis, S (1982) The action research reader, Victoria: Deakinn University Press.

Kidd, J.M. (2006) Understanding career counselling: theory, research and practice, London: Sage

Kolb, D (1984) Experiential learning: experience as the source of learning and development, Englewood Cliffs: Prentice Hall 
Law, B. (1996) Career education in a curriculum, in Watt, A.G., Law, B., Killeen, J, Kidd, J \& Hawthorn, R. (eds), Rethinking career education and guidance; theory, policy and practice, London: Prentice Hall

McMahon, $M$ and Patton,W (2006) Career counselling constructivist approaches, London: Routledge

McRoberts, C, Burlingame, G.M and Hoag, M.J (1998) Comparative efficacy of individual and group psychotherapy: a meta-analytic perspective, Group dynamics, 2: 101-17, http://dx.doi.org/10.1037/10892699.2.2.101

Maguire, M and Killeen, J (2003) Outcomes from career information and guidance services, Paris: OECD

Offer, M (200I) Career guidance in a group context in Gothard, B, Mignot, Phil, Offer M, Ruff, M (eds), Career guidance in context, London: Sage

Reid, $\mathrm{H}$ and West, L (20I I ) "Telling tales” Using narrative in career guidance, Journal of vocational behavior, Vol 78, 2: 174-183, http://dx.doiorg/10.1016/j. jvb.2010.10.001

Reid, H (2016) An introduction to career counselling and coaching, London: Sage

Rogers, C (196I) On becoming a person:The person centred approach, New York: Harper Row

Savickas, M (20I2) Life Design: a paradigm for career intervention in the 2 I st century, Journal of counseling and development, 90 (I): | 3-19, http://dx.doi.org/ I0.1 I I $\mathrm{I} / \mathrm{j} . \mathrm{I} 556-6676.2012 .00002$

Schon, D ( 1983) The reflective practitioner, New York: Basic Books

Skills Development Scotland (2012) Career management skills framework for Scotland. Glasgow: Skills Development Scotland.

Smith, M.L, Glass, G.V and Miller,T.I. (1980) The benefits of psychotherapy, Baltimore: John Hopkins University

Thomsen, $R$ (2012) Career guidance in communities, Aarhus: Aarhus University Press
Toseland, A and Sporin, M (1986) When to recommend group treatment, International journal of group psychotherapy, 36: I7I-20I.

Westergaard, J (2013) Group work: pleasure or pain? An effective guidance activity or a poor substitute for one-to-one interactions with young people, International journal for education and vocational guidance, vol. I 3 pp I73- |86, http://dx.doi.org/ 10.1007/s I0775$013-9249-8$

Westergaard, J (2009) Effective group work with young people, London: McGraw Hill Education.

Whiston, S.C., Brecheisen, B.K, Stephens (200I) Does treatment modality affect career counselling effectiveness?, Journal of vocational behaviour, 62: 3094 I0, http://dx.doi.org/ I0.10 I 6/S000 I-879I(02)00050-7

Whiston, S.C., Sexton, T.L and Lasoff, D.L (1998) Career interventions outcomes: a replication and extension of Oliver and Spokane (1988), Journal of counselling psychology 45 (2): I 50- I65, http://dx.doi. org/10.1037/0022-0167.45.2.150

Whitmore, J (2002) Coaching for performance, London: Nicolas Brealey.

Yates, J (2014) The career coaching handbook, London: Routledge

Young, R and Collin, A (2004) Introduction: constructivism and social constructivism in the career field, Journal of vocational behaviour Vol 64:374-388, http://dx.doi.org/10.1016/j.jvb.2003.12.005

\section{For correspondence}

Susan Meldrum

Lecturer in Career Guidance and Development, Edinburgh Napier University

s.meldrum@napier.ac.uk 